\title{
Evaluation of fetomaternal outcome in pregnancies complicated by heart disease: our experience at a tertiary care centre
}

\author{
Pankush Kapoor*, Raju Agarwal, Uttara A. Kohli, Tony Jose, Sanjay Singh
}

Department of Obstetrics and Gynaecology, Armed Forces Medical College, Pune, Maharashtra, India

Received: 06 May 2016

Accepted: 02 June 2016

\section{*Correspondence:}

Dr. Pankush Kapoor,

E-mail: lovepankush@gmail.com

Copyright: ( ) the author(s), publisher and licensee Medip Academy. This is an open-access article distributed under the terms of the Creative Commons Attribution Non-Commercial License, which permits unrestricted non-commercial use, distribution, and reproduction in any medium, provided the original work is properly cited.

\section{ABSTRACT}

Background: Heart disease is an important cause of indirect maternal deaths accounting for $20 \%$ of all cases, complicating approximately $1 \%$ of all pregnancies. During pregnancy, increased cardiac demands potentially increase morbidity and mortality in women with underlying heart disease. This study illustrates the fetomaternal outcome in pregnancies complicated by heart disease.

Methods: This study is a prospective observational study which was carried out from December 2013 to August 2015 at a tertiary care teaching hospital of armed forces India. A total of forty four pregnant women with heart disease were attended during the study period. Various parameters were used to measure maternal outcome like preterm labour, cesarean delivery, congestive cardiac failure, maternal mortality, while fetal outcome was measured in terms of low birth weight, prematurity, intrauterine growth restriction, perinatal mortality and intrauterine death.

Results: A total of 7545 pregnant women delivered during the study period, of which 94 were patients with heart disease giving a prevalence of $1.2 \%$. Acquired valvular heart lesions were found in 61 patients $(64.9 \%)$ with mitral valve being the commonest valve affected in 69 patients $(73.4 \%)$, others were congenital. Of the group, 89 patients were in NYHA class I and 05 in NYHA class II. Majority, 44 patients (46.8\%) delivered vaginally while 31 patients $(33 \%)$ underwent a cesarean delivery and 30 babies $(31.9 \%)$ were low birth weight. There was no neonatal mortality. Maternal mortality was low (1.1\%), while 43 (45.7\%) had obstetric complications.

Conclusions: Multidisciplinary team approach involving obstetrician, neonatologist, cardiologist and anesthesiologist led to the favorable outcome in our study. Key determinant of adverse fetomaternal outcome was the poor functional class of NYHA.

Keywords: Pregnancy, Heart disease, Complications

\section{INTRODUCTION}

Heart disease complicates $>1 \%$ of all pregnancies and is now the leading cause of indirect maternal deaths accounting for $20 \%$ of all cases (Simpson, 2012). Remarkable changes involving the heart and the circulation happen during pregnancy and puerperium. The association is of risk to the mother as pregnancy places an extra mechanical burden on the diseased heart of the pregnant patient. ${ }^{1}$

Improvements in health care services in recent decades have permitted more frequent identification of pregnant women with congenital and acquired heart disease. Cardiovascular disease is the most important nonobstetric cause of disability and death in pregnant woman occurring in 0.4 to $4.0 \%$ pregnancies. ${ }^{2}$ The reported maternal mortality rate ranges from $0.4 \%$ in patients with New York heart association (NYHA) classification I and II to $6.8 \%$ or higher among patients with classification III and IV severity. It is not surprising that added hemodynamic burden of pregnancy, labor and delivery can aggravate symptoms and precipitate complications in a woman with pre-existing cardiac disease. In this study, we intend to evaluate the maternal as well as the fetal outcome in pregnancies complicated by heart disease. 


\section{METHODS}

This study was a prospective observational study conducted at a tertiary care teaching hospital of Armed Forces India. All antenatal women with a recently diagnosed heart disease during booking ANC visit or already diagnosed to be having heart disease were enrolled in the study. Cases were referred to cardiologist for confirmation of cardiac disease; know the functional status of the heart and to seek their opinion regarding management. Detailed history with regards to cardiac lesion was asked. Thorough clinical examination was done to find out the type of cardiac lesion, any signs of failure and stage of pregnancy. Cases were graded as per NYHA classification of grade of heart disease. Patients were counseled regarding the importance of rest, medication and regular antenatal visits. Patients were discharged on $6^{\text {th }} / 7^{\text {th }}$ post natal day with advice regarding contraception, breast feeding and regular medications for the cardiac lesion if any.

The study included 94 pregnant patients who were registered, admitted and delivered at the hospital from September 2012 to August 2015. Case notes of all the patients with heart disease who delivered during the study period were reviewed and evaluated. Patients were admitted for obstetric and medical indications. Apart from antenatal investigations, ECG and 2D echocardiography were also done and all patients were evaluated by the cardiologist. Patients in NYHA class I and II were managed on OPD basis and were admitted at 38 weeks period of gestation for safe confinement. Maternal outcome was measured in terms of maternal mortality, preterm labour, cesarean delivery, and congestive cardiac failure while fetal outcome was measured in terms of prematurity, intrauterine growth restriction, low birth weight, perinatal mortality and intrauterine death.

\section{RESULTS}

Table 1: Age distribution pattern.

\begin{tabular}{|lll|}
\hline $\begin{array}{l}\text { Age } \\
\text { distribution }\end{array}$ & $\begin{array}{l}\text { Number of } \\
\text { patients }\end{array}$ & $\begin{array}{l}\text { Percentage } \\
(\%)\end{array}$ \\
\hline$\leq 20$ & 13 & 13.8 \\
\hline $21-25$ & 41 & 43.6 \\
\hline $26-30$ & 29 & 30.8 \\
\hline $31-35$ & 07 & 7.4 \\
\hline$>35$ & 04 & 4.3 \\
\hline Total & 94 & 100.0 \\
\hline
\end{tabular}

In this study, 94 cases of pregnancy with heart disease delivered from September 2012 to August 2015 over a period of three years. During this period there were a total of 7545 births giving an incidence of $1.2 \%$.

Out of 94 cases $13(13.8 \%)$ were teenage pregnancies, 41 $(43.6 \%)$ were in the age group of $21-25$ years, $29(30.8 \%)$ were in the age group of 26-30 years, 7 (7.4\%) in the age group of $31-35$ years and 4 cases $(4.3 \%)$ were in the age group of $>35$ years ( Table 1 ).

Analysis of the type of cardiac pathology found in this study showed rheumatic heart disease to be the predominant lesion in 61 cases $(64.9 \%)$. Congenital heart disease was found in 16 cases (17\%) and 17 cases $(18.1 \%)$ had other heart lesions (Table 2).

Table 2: Type of cardiac lesion in pregnant women with heart disease.

\begin{tabular}{|lll|}
\hline Heart disease & $\begin{array}{l}\text { Number of } \\
\text { patients }\end{array}$ & $\begin{array}{l}\text { Percentage } \\
(\%)\end{array}$ \\
\hline Rheumatic heart disease & 61 & 64.9 \\
\hline Congenital heart disease & 16 & 17.0 \\
\hline Other acquired lesions & 17 & 18.1 \\
\hline Total & 94 & 100.0 \\
\hline
\end{tabular}

Mitral valve was the most commonly affected valve seen in 69 cases $(73.4 \%)$. Aortic valve was affected in 19 cases $(20.2 \%)$ and other lesions were encountered in 18 cases $(19.1 \%)$. Tricuspid valve was affected in 13 cases (13.8\%) (Table 3).

Table 3: Distribution of type of valvular involvement pattern.

\begin{tabular}{|lll|}
\hline $\begin{array}{l}\text { Type of } \\
\text { valve involved }\end{array}$ & $\begin{array}{l}\text { Number of } \\
\text { patients }\end{array}$ & $\begin{array}{l}\text { Percentage } \\
(\%)\end{array}$ \\
\hline Mitral valve & 69 & 73.4 \\
\hline Tricuspid valve & 13 & 13.8 \\
\hline Aortic valve & 19 & 20.2 \\
\hline Other valvular lesions & 18 & 19.1 \\
\hline
\end{tabular}

Analysis of the type of heart lesion affecting various valves showed that regurgitate lesion was the predominant lesion found in 63 cases $(67 \%)$. Stenotic lesion on the other hand was seen in 31 cases $(33 \%)$. Combined stenotic and regurgitate lesion was seen affecting 19 cases $(20.2 \%)$. Septal defects on the other hand were seen in 10 cases $(10.6 \%)$. Valve prolapse was seen in 14 cases $(14.9 \%)$ (Table 4$)$.

Table 4: Type of heart lesion.

\begin{tabular}{|lcc|}
\hline Type of lesion & Number & Percentage (\%) \\
\hline Stenotic lesion & 31 & 33.0 \\
\hline Regurgitant lesion & 63 & 67.0 \\
\hline Stenotic+regurgitant lesion & 19 & 20.2 \\
\hline Septal defects & 10 & 10.6 \\
\hline Valve prolapse & 14 & 14.9 \\
\hline
\end{tabular}

Pulmonary artery hypertension was present in 13 cases $(13.8 \%)$. Surgically corrected heart lesions were seen in 21 cases $(22.3 \%)$. A majority of patients with rheumatic heart disease were in New York heart association 
(NYHA) class I. 89 patients $(94.7 \%)$ were in class I and 05 patients $(5.3 \%)$ were in class II while no patient in our study was in class III or IV.

Out of 94 cases of pregnancy with heart disease 44 patients $(46.8 \%)$ had a normal vaginal delivery, 31 patients $(33 \%)$ underwent a caesarean section. 19 patients $(20.2 \%)$ had an instrumental delivery mainly to cut down the $2^{\text {nd }}$ stage of labor (Table 5).

Table 5: Maternal outcome in terms of mode of delivery.

\begin{tabular}{|lll|}
\hline Mode of delivery & $\begin{array}{l}\text { Number of } \\
\text { patients }\end{array}$ & $\begin{array}{l}\text { Percentage } \\
(\%)\end{array}$ \\
\hline Normal & 44 & 46.8 \\
\hline Elective LSCS & 17 & 18.1 \\
\hline Emergency LSCS & 14 & 14.9 \\
\hline Instrumental & 19 & 20.2 \\
\hline Total & 94 & 100.0 \\
\hline
\end{tabular}

Analysis of the fetal outcome in terms of various parameters revealed that out of 95 neonates $(93+01$ DADC twin delivery) born to pregnant patients with heart disease, 10 neonates $(10.5 \%)$ were born preterm, 04 neonates $(4.2 \%)$ had intrauterine growth restriction, 05 neonates $(5.3 \%)$ had to be admitted in NICU. However there was no intrauterine fetal death observed (Table 6).

Table 6: Fetal outcome in patients with heart disease.

\begin{tabular}{|lll|}
\hline Outcome & Number & Percentage (\%) \\
\hline Preterm & 10 & 10.5 \\
\hline IUGR & 04 & 4.2 \\
\hline Intrauterine fetal death & Nil & 0.0 \\
\hline Neonatal mortality & Nil & 0.0 \\
\hline NICU stay & 05 & 5.3 \\
\hline
\end{tabular}

Table 7: Maternal morbidity and mortality distribution pattern.

\begin{tabular}{|lll|}
\hline Morbidity/mortality & $\begin{array}{l}\text { Number of } \\
\text { patients }\end{array}$ & $\begin{array}{l}\text { Percentage } \\
(\%)\end{array}$ \\
\hline Cardiac failure & 07 & 7.4 \\
\hline Maternal mortality & 01 & 1.1 \\
\hline Total & 94 & 100.0 \\
\hline
\end{tabular}

Of the total 95 neonates born to pregnant patients with heart disease 30 neonates $(31.9 \%)$ were born with low birth weight while 65 neonates $(69.1 \%)$ had a normal birth weight.

There was no neonatal morbidity or mortality observed during the study. 7 out of 94 patients $(7.4 \%)$ went into failure and had to be admitted to ICU. Of these 4 patients, 2 patients were in NYHA Class II. However there was 1 maternal mortality out of 94 cases $(1.1 \%$ ) (Table 7$)$.

\section{DISCUSSION}

Pregnancy is an event of added stress in a cardiac patient. Cardiac disease continues to be a risk factor for maternal and neonatal morbidity and mortality. This study reflects the maternal and fetal outcome in pregnant women with cardiac disease managed at a tertiary care teaching hospital of the armed forces India.

Maternal heart disease is one of the most important causes of maternal death. In the developing countries rheumatic heart disease remains the major cause of maternal heart disease while in developed countries maternal congenital heart disease has become more prevalent due to improved survival of children with congenital heart disease. In our study the incidence of the cardiac disease was $1.24 \%$ which is very close to the study carried out by Asghar et al (0.98\%). ${ }^{3}$ Another study done by Vidyadhar B et al showed similar incidence of $1.3 \%$. $^{4}$ Similar comparable results with an incidence of $1.3 \%$ was found in a study done at PGIMER Chandigarh on pregnancy with heart disease. ${ }^{5}$

Analysis of the type of cardiac pathology found in this study showed rheumatic heart disease to be the commonest $(64.9 \%)$ while congenital heart disease was found in 16 cases $(17 \%)$ and 17 cases $(18.1 \%)$ had other heart lesions. (Table 2) Thus, rheumatic heart disease was the commonest etiology found. These results were comparable to other Indian studies by Pratibha D et al $(62.6 \%)$ and Vidyadhar B et al $(77 \%)$. Samuel W et al also reported the incidence of rheumatic heart disease to be around $55.7 \%$.,6,7

The ratio of rheumatic heart disease to congenital heart disease was 3:1 (64.9:17) which was comparable to study performed by Asghar et al. Similar results were shown in other studies like Walkiria $S$ et al $(55.7: 19.1) .{ }^{3,7}$ Globally rheumatic heart disease still remains the commonest heart disease associated with pregnancy as seen in various studies from India and other countries.

Among pregnant patients with heart disease mitral valve was the commonest valve affected in $73.4 \%$ of the cases and aortic valve affected in $20.2 \%$ of cases. Similar results were seen in various other studies which showed mitral valve to be the predominant affected valve. Studies by Pratibha D et al, Vidyadhar B et al and Samuel W et al showed mitral stenosis to be the predominant valvular affection in patients with heart disease. ${ }^{4,6,7}$ However in our study, mitral regurgitation was the predominant lesion which was seen in 54 cases $(57.4 \%)$ while mitral stenosis was seen in 25 cases $(26.6 \%)$. Most other Indian $\&$ western studies have also shown mitral stenosis as the commonest valvular lesion.

The majority of pregnant patients with heart disease in the present study were in class I $(94.7 \%)$ and $5.3 \%$ in class II. There were no patients in class III or class IV. Various studies report varying frequencies of the severity 
of dyspnea. Deshmukh et al found majority of their patients $(62.7 \%)$ to be in class I. Similar results were shown in the study done at PGIMER Chandigarh. However studies by Sawhney et al $(22.6 \%)$ and Pratibha $\mathrm{D}$ et al $(28 \%)$ reported higher percentage of patients in class III and class IV. ${ }^{8,6}$ This difference may be due to higher number of unbooked cases in their study.

Out of total 94 patients 44 patients $(46.8 \%)$ had a normal vaginal delivery while 31 patients $(33 \%)$ underwent a cesarean delivery and 19 patients (20.2\%) underwent instrumental delivery (vacuum delivery in our study) to cut down the second stage of labor. Out of the 31 patients who underwent a cesarean delivery, 17 patients underwent elective cesarean delivery for various obstetric indications and 14 underwent emergency cesarean delivery. ${ }^{16}$ Different authors have reported different figures. The rate of normal vaginal delivery to cesarean delivery as found in the present study (46.8\%:33\%) is different in respect to the results of the other studies by Pratibha D et al (73.5:23.5) and Vidyadhar B et al (62:17). These variable Figures in different studies could be due to the various obstetric indications which required cesarean section or instrumental deliveries. ${ }^{6,4}$

The incidences of premature babies, intrauterine growth restriction, still birth were not increased in pregnant patients with heart disease as compared to the general population of pregnant women. A total of 10 neonates $(10.6 \%)$ were born preterm, 4 neonates $(4.2 \%)$ had intrauterine growth restriction. There were no intrauterine deaths. 5 neonates $(5.3 \%)$ had to be kept in the NICU for birth asphyxia. There was no perinatal mortality seen. Samuel W et al reported a similar incidence (13\%) of preterm neonates in their study. Sawhney et al too reported an incidence of $12 \%$ in their study. Pratibha D et al $(9.4 \%)$ and Vidyadhar B et al $(11 \%)$ also reported similar incidence. ${ }^{4,6-8}$

Analysis of the birth weight of the neonates in the present study showed the incidence of low birth weight neonates to be around $31.9 \%$. Other studies have reported varying results. Sawhney et al reported it to be around $18.2 \%$, while Pratibha D et al $(37.4 \%)$ and Vidyadhar B et al $(60 \%)$ reported a higher incidence of low birth weight neonates. ${ }^{4,6}$ The incidence of low birth weight neonates seem to be increased in neonates born to pregnant women with heart disease as compared to the incidence found in the general population which is around $20 \%$.

There were more cardiac complications during pregnancy in the non-operated group which is similar to that reported by various other studies. ${ }^{1,9}$ In the present study 7 cases $(7.4 \%)$ went into failure, all of these patients had a non-operated cardiac lesion and had to be admitted in the ICU. In the present study, maternal mortality was seen in 1 patient with an incidence of $1.1 \%$. Out of the 5 patients in NYHA class II, 1 had a maternal mortality. Similar results were reported from various other Indian and international studies. Samuel $\mathrm{W}$ et al reported an incidence of maternal deaths to be around $2.7 \%$, Sawhney et al reported an incidence of $2.1 \%$ while Pratibha D et al reported it to be around $0.9 \% .^{7-9}$ Anantha Subramaniam have reported $4(2.9 \%)$ maternal deaths among 136 patients. $10,11-16$

\section{CONCLUSION}

Cardiac disease during pregnancy needs to be given utmost priority. Our study is limited by the smaller sample size of the study, had no control group and it was limited to one medical centre only. However results of this study can be generalised to the population, as it was representative of the population studied and results were comparable to other studies.

Today most women with heart disease can be brought safely through pregnancy without major risks for themselves or the unborn child. Good antenatal care combined with obstetric, neonatologist, cardiologist and anesthesiologists i.e. a multi-disciplinary combined approach can bring about successful outcome in pregnancies complicated by heart disease. Early detection and treatment of cardiac complications, anemia, and pregnancy induced hypertension will contribute towards favourable maternal and neonatal outcome. Use of prophylactic antibiotics, anti-failure treatment during labor may bring down the incidence of infective endocarditis and cardiac failure during antenatal as well as puerperal period. Use of prophylactic anticoagulants in high risk patients may prevent development of embolism in pregnant patients with heart disease. The good results of this study can be attributed to the multidisciplinary approach of obstetrician, neonatologist, cardiologist and anaesthesiologist. Adverse fetomaternal outcome was related to poor functional class of NYHA.

Funding: No funding sources Conflict of interest: None declared

Ethical approval: The study was approved by the Institutional Ethics Committee

\section{REFERENCES}

1. Cunningham FG, Leveno KJ, Bloom SL, Spong CY, Dashe JS, Hoffman BL, et al. Williams obstetrics, $24^{\text {th }}$ Edition, Appleton and lange; 2014:973.

2. Grewal M, Biswas MK, Perloff D. Cardiac, hematologic, palmonary, renal and urinary tract disorder in pregnancy. In Decherney $\mathrm{AH}$, Nathan (Eds). Current Obstetrics and Gynaecologic Diagnosis and Treatment, $9^{\text {th }}$ Edition; 1991:387-427.

3. Asghar F, Kokab H, Evaluation and outcome of pregnancy complicated by heart disease. J Pak Med Assoc. 2005;19:1-2.

4. Bangal VB, Singh RK, Shinde KK. Clinical study of heart disease complicating pregnancy. IOSR Journal of Pharmacy. 2012;2(4):25-8.

5. Guleria R, Vashist K, Dhall GI, Grover A, Wahi PL, Pregnancy with heart disease. Experience at 
PGIMER, Chandigarh. $\mathrm{J}$ of Physicians of India. 1990;38:902-6.

6. Pratibha D, Kiranmai D, Rani VU, Vani NG. Pregnancy outcome in chronic rheumatic heart disease . J Obstet Gynecol India. 2009;59(1):41-6.

7. Avila WS, Rossi EG, Ramires JA, Grinberg M, Bortolotto MR, Zugaib M. Pregnancy in patients with heart disease: experience with 1,000 cases. Clin Cardiol. 2003;26(3):135-42.

8. Sawhney H, Aggarwal N, Suri V, Vasishta K, Sharma Y, Grover A. Maternal and perinatal outcome in rheumatic heart disease. Int J Gynaecol Obstet. 2003;80:9-14.

9. Arias F. Practical guide to high risk pregnancy and delivery, $2^{\text {nd }}$ edition; 1992:572.

10. Subramaniam AL, Subramaniam AC, Geetha N. Pregnancy and labor in cardiac patients. Obst Gynae India. 1980;30:479-82.

11. Elkayam U, Gleicher N. Cardiac problems in pregnancy: diagnosis and management of maternal and fetal heart disease $3^{\text {rd }} \mathrm{Ed} ; 1998$.
12. Creasy PK, Resnik R. Maternal and fetal medicine. Principles and practice, $2^{\text {nd }}$ ed. Philadelphia; 2013.

13. Braunwald. Heart disease: A Textbook of Cardiovascular Medicine, $6^{\text {th }}$ ed., Copyright $(C$, WB Saunders Company; 2001:1846-1850.

14. Naderi S, Raymond R. Pregnancy and heart disease: Cleveland clinic practice based pharmacology, published; 2014.

15. Cantwell R, Brock TC, Cooper G, Dawson A, Drife J, Garrod D, et al. Centre for maternal and child enquiries. Saving mothers' lives: reviewing maternal deaths to make motherhood safer: 2006-08. The eighth report on confidential enquiries into Maternal Deaths in the United Kingdom. BJOG. 2011;118(Suppl 1):1-203.

16. Regitz-Zagrosek V, Blomstrom Lundqvist C, Borghi C, Cifkova R, Ferreira R, Foidart JM, et al. ESC guidelines on the management of cardiovascular diseases during pregnancy. European Heart Journal. 2011;32:3147-97.

Cite this article as: Kapoor $\mathrm{P}$, Agarwal R, Kohli UA, Jose T, Singh S. Evaluation of fetomaternal outcome in pregnancies complicated by heart disease: our experience at a tertiary care centre. Int $\mathbf{J}$ Reprod Contracept Obstet Gynecol 2016;5:2269-73. 